\title{
Second and Third Order Aberrations of the Compensated Quadrupole Doublet
}

\author{
F. W. Martin
}

Nanobeam Corporation, 50 Village Ave., Dedham MA 02026

The doublet of quadrupole lenses has not been historically successful in producing the small probes needed in microscopy, most likely on account of aberrations produced by small deviations from perfect quadrupole symmetry in the lens structure [1]. To counteract these aberrations, voltages can be used on multipole lenses fabricated with the same principal plane as the quadrupole lenses. A simple account is therefore needed for aperture aberrations of the doublet produced by multipoles inside of its two lenses.

The general formula for the potential in cylindrical coordinates has terms of the form

$$
\mathrm{V}(\mathrm{r}, \mathrm{t})=\mathrm{V}_{\mathrm{n}}(\mathrm{r} / \mathrm{R})^{\mathrm{n}} \cos \mathrm{n}\left(\mathrm{t}-\mathrm{t}_{\mathrm{p}}\right)
$$

which fit to a lens with $2 \mathrm{n}$ poles at radius $\mathrm{R}$ with alternating voltages $+-\mathrm{V}_{\mathrm{n}}$. In the impulse approximation a particle experiences a force given by the negative of the gradient of the potential as it travels through a lens with length $\mathrm{L}$ and acquires a transverse velocity. in addition to its assumed constant longitudinal velocity. It emerges with an angular deviation given by

$$
\begin{aligned}
& \mathrm{w}_{\mathrm{x}}=-\mathrm{S}_{\mathrm{n}} \mathrm{r}^{\mathrm{n}-1} \cos \left[(\mathrm{n}-1) \mathrm{t}-\mathrm{nt}_{\mathrm{p}}\right] \\
& \mathrm{w}_{\mathrm{y}}=+\mathrm{S}_{\mathrm{n}} \mathrm{r}^{\mathrm{n}-1} \sin \left[(\mathrm{n}-1) \mathrm{t}-\mathrm{nt}_{\mathrm{p}}\right]
\end{aligned}
$$

where the multipole strength is $\mathrm{S}_{\mathrm{n}}=(\mathrm{n} / 2)\left(\mathrm{V}_{\mathrm{n}} / \mathrm{V}_{\mathrm{A}}\right)\left(\mathrm{L} / \mathrm{R}^{4}\right)$ and $\mathrm{qV}_{\mathrm{A}}$ is the particle energy. When $\mathrm{n}=3,4$ there are hexapole and octopole terms. Setting $\mathrm{t}_{\mathrm{p}}=90^{\circ} / \mathrm{n}$ turns the cosine factor into a sine and produces forces everywhere perpendicular to those from terms with $t_{p}=0$. For octopoles an inclination of 22.5 degrees is required, splitting the angle between poles.

As the particle travels outside the quadrupole lens by a throw distance, such as the intermediate image distance $\mathrm{v}_{\mathrm{ux}}$ in the $\mathrm{x}$ section, the angular deviation alters the location of the line image produced by the quadrupole. Next the altered position of the intermediate image produced by the upstream lens is magnified by the downstream lens, so that both lenses produce an aberration at the final focus such as

$$
\mathrm{x}=\mathrm{v} \mathrm{w}_{\mathrm{dx}}+\mathrm{M}_{\mathrm{dx}} \mathrm{v}_{\mathrm{ux}} \mathrm{W}_{\mathrm{ux}}=\mathrm{v} \mathrm{w}_{\mathrm{dx}}+\mathrm{M}_{\mathrm{x}} \mathrm{u} \mathrm{w}_{\mathrm{ux}}
$$

To convert this expression into the image-side paraxial angles $(a, b)$ at the focus it is convenient to use the run-out ratio $\mathrm{p}=\mathrm{x}_{\mathrm{d}} / \mathrm{x}_{\mathrm{u}}=-\mathrm{v} /\left(\mathrm{M}_{\mathrm{x}} \mathrm{u}\right)>1$ and the run-in ratio $\mathrm{q}=\mathrm{y}_{\mathrm{d}} / \mathrm{y}_{\mathrm{u}}=-\mathrm{v} /\left(\mathrm{M}_{\mathrm{y}} \mathrm{u}\right)<1$ (where $\left(\mathrm{x}_{\mathrm{i},} \mathrm{y}_{\mathrm{i}}\right)$ indicates the excursion of a ray from an on-axis source in lens $\mathrm{i}, \mathrm{v}$ is the distance to the stigmatic object, $\left(\mathrm{M}_{\mathrm{x}}, \mathrm{M}_{\mathrm{y}}\right)$ are the magnifications of the doublet, and $\mathrm{u}$ is the object distance). When the terms in successive lenses are converted to rectangular coordinates the net result for hexapoles is

$$
\begin{aligned}
& x=A_{3} a^{2}+2 B_{3} a b+C_{3} b^{3} \\
& y=B_{3} a^{2}+2 C_{3} a b+D_{3} b^{3}
\end{aligned}
$$

with coefficients given in Table 1 while for octopoles it is 


$$
\begin{aligned}
& x=A a^{3}+3 B a^{2} b+3 C a b^{2}+D b^{3} \\
& y=B a^{3}+3 C a^{2} b+3 D a b^{2}+E b^{3}
\end{aligned}
$$

with coefficients given in Table 2 .

\begin{tabular}{ll}
\hline 1. Second-order aberration coefficients & 2. Third-order aberration coefficients \\
\hline & \\
$A_{3}=+\left(D_{3 c}-U_{3 c} p^{-3}\right) v^{3}$ & $A=-\left(D_{4 c}-U_{4 c} p^{-4}\right) v^{4}$ \\
$2 B_{3}=+2\left(D_{3 c}-U_{3 c} p^{-2} q^{-1}\right) v^{3}$ & $3 B=-3\left(D_{4 s}-U_{4 s} p^{-3} q^{-1}\right) v^{4}$ \\
$C_{3}=-\left(D_{3 c}-U_{3 c} p^{-1} q^{-2}\right) v^{3}$ & $3 C=3\left(D_{4 c}-U_{4 c} p^{-2} q^{-2}\right) v^{4}$ \\
$B_{3}=+\left(D_{3 c}-U_{3 c} p^{-2} q^{-1}\right) v^{3}$ & $D=\left(D_{4 s}-U_{4 s} p^{-1} q^{-3}\right) v^{4}$ \\
$2 C_{3}=-2\left(D_{3 c}-U_{3 c} p^{-1} q^{-2}\right) v^{3}$ & $B=-\left(D_{4 s}-U_{4 s} p^{-3} q^{-1}\right) v^{4}$ \\
$D_{3}=-\left(D_{3 c}-U_{3 c} q^{-3}\right) v^{3}$ & $3 C=3\left(D_{4 c}-U_{4 c} p^{-2} q^{-2}\right) v^{4}$ \\
& $3 D=3\left(D_{4 s}-U_{4 s} p^{-1} q^{-3}\right) v^{4}$ \\
& $E=-\left(D_{4 c}-U_{4 c} q^{-4}\right) v^{4}$ \\
\hline
\end{tabular}

Table 2 shows that A, C, E are determined only by the normal octopoles, while B, D are set only by the skew octopoles. E is the largest coefficient and is in practice determined by the strength $U_{4 \mathrm{c}}$ of the upstream octopole, because $\mathrm{q}^{-4}$ is large...

Aberrations produced by such compensating octopoles add to the aberrations already present, which are a) those inherent in a quadrupole doublet of perfect symmetry [2], and b) those at the crossover object produced by spherical aberration in the condenser lens. Although 4 octopoles are enough to cancel only the parasites, a fifth octopole is required between the lenses to cancel these aberrations. Then

$$
\begin{array}{lll}
A=0=-\left(D_{4 c}-U_{4 c} p^{-4}\right) v^{4} & -L_{4 c}\left(t_{x} M_{d x}\right)^{4} & +C_{s} M_{x}{ }^{4} \\
C=0=\left(D_{4 c}-U_{4 c} p^{-2} q^{-2}\right) v^{4} & +L_{4 c}\left(t_{x} M_{d x}\right)^{2}\left(t_{y} M_{d y}\right)^{4} & +(1 / 3) C_{s}\left(M_{x} M_{y}\right)^{2} \\
E=0=-\left(D_{4 c}-U_{4 c} q^{-4}\right) v^{4} & -L_{4 c}\left(t_{y} M_{d y}\right)^{4} & +C_{s} M_{y}^{4}
\end{array}
$$

where $\mathrm{U}_{4 \mathrm{c}}$ now contains inherent and parasitic strengths and a compensating strength proportional to octopole voltage $\mathrm{Uc}, \mathrm{L}_{4 \mathrm{c}}$ is the strength of the additional normal octopole, $\mathrm{t}_{\mathrm{x}}$ and $\mathrm{t}_{\mathrm{y}}$ are throw distances from it to the intermediate images, and $\mathrm{C}_{\mathrm{s}}$ is the spherical aberration coefficient of the condenser lens. In practice it is found that a) $U_{4 c}$ sets $\left.E, b\right) D_{4 c}$ sets $A$, and c) using $U_{4 c}$ and $L_{4 c}$ in the proper ratio to keep E unaffected sets $\mathrm{C}$, with almost no effect on A [3]. Similar equations apply for B, D, and to the $\mathrm{n}=3$ case, where $\mathrm{A}_{3}, \mathrm{~B}_{3}, \mathrm{C}_{3}, \mathrm{D}_{3}$ may be set to zero with 4 compensating hexapoles [4].

Expressions of this sort may enable the techniques usually applied for mid-column correctors (rapid computer-analyzed image processing and highly accurate, stable voltage supplies) to improve the performance of focused ion beam systems.

[1] P. W. Hawkes, Quadrupoles in Electron Lens Design (Academic, NY) p. 65.

[2] T. Ya. Fishkova et al, Soviet Phys. Tech. Phys. 13 (1968) p. 520.

[3] F. W. Martin, submitted to Optik.

[4] F. W. Martin, submitted to Microscopy and Microanalysis. 